\title{
Ischemic stroke in a patient with Crohn's disease

\author{
A confirmed paradoxical embolism mechanism
}

\author{
Marcos C. Lange, Laura N. Zamproni, Vera Braatz, \\ Artur F. Fernandes, Viviane F. Zetola, Edison M. Nóvak
}

Ischemic stroke (IS) in young adults is challenging because no etiology is found in about $30 \%$ of these patients, and therefore, they are classified as cryptogenic IS ${ }^{1}$. It is now recognized that the prevalence of a patent foramen ovale (PFO) is higher in this population ${ }^{2}$. However, the simple existence of a right-to-left shunt (RLS) does not seems to be enough to explain the mechanism of the IS, and other significant factors must be present $t^{3}$. The aim of this study is to report a patient with Crohn's disease (CD) who presented with an IS after the withdrawal of a central venous catheter (CVC) due to an embolus from the right atrium through an undiagnosed $\mathrm{PFO}$.

\section{CASE}

The patient was a white, 45-year-old male with a diagnosis of CD 20 years ago. He was admitted to the hospital for total parenteral nutrition through a CVC in his right internal jugular vein because of an enterocutaneous fistula. Ten days later during the withdrawal of the $\mathrm{CVC}$, the patient presented a generalized tonic-clonic seizure and persisted with impaired consciousness (Glasgow Coma Scale=9), partial gaze palsy, partial facial palsy, and left hemiplegia (NIH stroke scale=19). The brain CT was normal, and the brain MRI showed the presence of ischemic lesions localized in the right thalamus, the bilater-

\section{Correspondence}

Marcos Christiano Lange Rua General Carneiro $181 / 4^{\circ}$ andar Hospital das Clínicas

Serviço de Neurologia 80060-900 Curitiba PR - Brasil

E-mail: lange@ufpr.br

Received 28 June 2009

Received in final form 16 September 2009 Accepted 23 September 2009

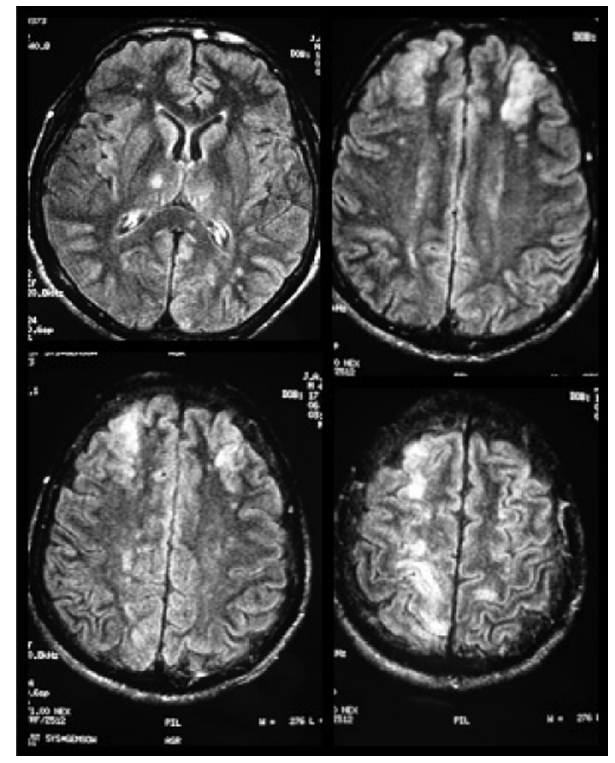

Fig 1. Ischemic stroke with an emboligenic pattern (cortical) observed by an axial brain MRI (FLAIR).

of high intensity transitory signals in a curtain pattern during rest and with a Valsalva's maneuver test. The contrast-enhanced transesophageal echocardiography confirmed the presence of a PFO and demonstrated an atrial septum aneurism (ASA) and the existence of a right atrial thrombus of $2.5 \times 0.3 \mathrm{~cm}$ near the interatrial septum (Fig 2). Oral anticoagulation therapy (warfarin) was introduced as secondary stroke prevention. In the following days, the patient's level of the conscience improved, but the left hemiplegia persisted. The modified Rankin Scale was a 3 after 30 days, 2 after 90 days, and 1 after 270 days.

\section{ACIDENTE VASCULAR ISOUEMICO EM PACIENTE COM DOENÇA DE CROHN: UM EMBOLISMO DE MECANISMO} PARADOXAL CONFIRMADO

Cerebrovascular Diseases Unit, Neurology Division, Internal Medicine Department, Clinical Hospital, Federal University of Paraná, Curitiba PR, Brazil. 


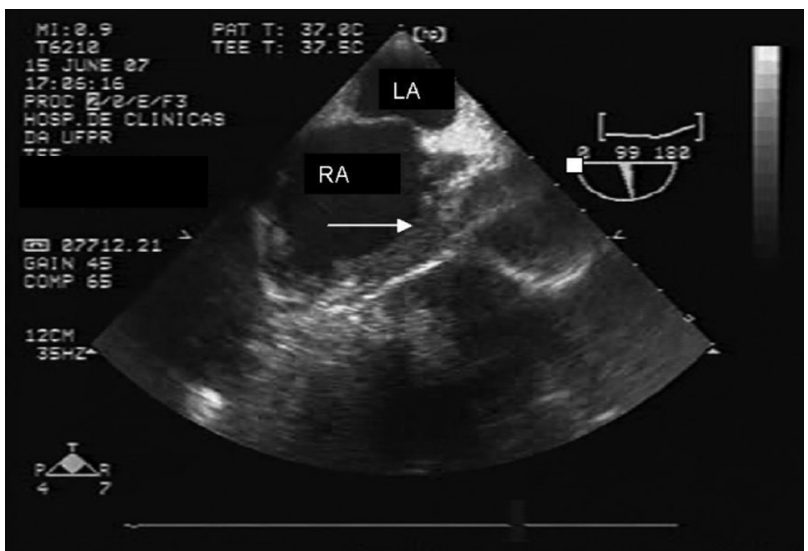

Fig 2. Transesophageal echocardiography demonstrating an interatrial septum aneurysm characterized by a left atrium (LA) interatrial septum dislocation and a right atrium (RA) thrombus (arrows).

\section{DISCUSSION}

In the present case, we demonstrated a direct relationship between the PFO and IS in a patient with a thrombophilic status secondary to the active phase of $\mathrm{CD}$. The PFO and ASA may be related to IS when in combination with other risk factors (thrombophilia, deep venous thrombosis), with a Valsalva maneuver immediately preceding the symptoms, and with an embolic pattern (cortical stroke) by brain $\mathrm{MRI}^{3-5}$. In the present case, the RLS was an unrecognized diagnosis, and two important factors for intravascular thrombosis were present: the active phase of $C D$ and the presence of a CVC. These two conditions could contribute to the emboligenic IS.

Inflammatory bowel disease patients have a higher prevalence of thrombophilic defects, and this hypercoagulability status could be related to the pathogenic mechanisms of cerebral ischemia during the active phase of $\mathrm{CD}^{6,7}$. Our patient was in the active phase of $\mathrm{CD}$, and this probably increased the chance of thrombus formation around the CVC.

CVCs are widely used in clinical practice to administer parenteral nutrition, vasoactive drugs, hemodialysis, and plasmapheresis. A previous necropsy study showed that $29 \%$ of patients with a CVC have a thrombus independently of the subjacent disease, suggesting that the presence of the catheter is a thrombophilic status ${ }^{8,9}$. Previous studies described simultaneous IS immediately after the withdrawal of the CVC in patients with lymphoblastic leukemia and unrecognized RLS ${ }^{10}$.

The current patient presented an IS secondary to a paradoxical embolism through an unrecognized PFO. The thrombus was generated in the right atrium by a combination of two hypercoagulability mechanisms, the active phase of CD and a CVC. These conditions are not unusual in daily clinical practice, but are usually neglected. The precise identification of a thrombogenic status could help determine which patients can exclude a RLS, facilitating the prevention of cryptogenic IS with the current therapies.

\section{REFERENCES}

1. Zétola VH, Nóvak EM, Camargo $\mathrm{CH}$, et al. Stroke in young adults: analysis of 164 patients. Arq Neuropsiquiatr 2001;59:740-745

2. Cabanes L, Mas JL, Cohen A, et al. Atrial septal aneurysm and patent foramen ovale as risk factors for cryptogenic stroke in patients less than 55 years of age: a study using transesophageal echocardiography. Stroke 1993;24: 1865-1873.

3. Ozdemir AO, Tamayo A, Munoz C, Dias B, Spence JD. Cryptogenic stroke and patent foramen ovale: clinical clues to paradoxical embolism. J Neurol Sci 2008;275:121-127.

4. Bogousslavsky J, Garazy S, Jeanrenaud X, Aebischer N, Van Melle G. Stroke recurrence in patients with patent foramen ovale: The Lausanne Study. Neurology 1996;46:1301-1305.

5. Steiner MM, Di Tullio MR, Rundek T, et al. Patent foramen ovale size and embolic brain imaging findings among patients with ischemic stroke. Stroke 1998;29:944-948.

6. Magro F, Dinis-Ribeiro M, Araújo FM, et al. High prevalence of combined thrombophilic abnormalities in patients with inflammatory bowel disease. Eur J Gastroenterol Hepatol 2003;15:1157-1163.

7. Santos S, Casadevall T, Pascual LF, et al. Neurological alterations related to Crohn's disease. Rev Neurol 2001;32:1158-1162.

8. Ducatman BS, McMichan JC, Edwards WD. Catheter-induced lesions of the right side of the heart: a one-year prospective study of 141 autopsies. J Am Med Assoc 1985;253:791-795.

9. Chakravarthy A, Edwards WD, Fleming CR. Fatal tricuspid valve obstruction due to a large infected thrombus attached to a Hickman catheter. J Am Med Assoc 1987; 257:801-803

10. Zuha R, Price T, Powles T, Treleaven J. Paradoxical emboli after central venous catheter removal. Ann Oncol 2000;11:885-886. 